\title{
ARQUEOLOGIA EXPERIMENTAL GUARANI NA FORMAÇÃO DE PROFESSORES(AS) EM CIÊNCIAS HUMANAS: UMA EXPERIÊNCIA NA CIDADE MISSIONEIRA DE SÃO BORJA
}

Viviane Pouey Vidal ${ }^{1}$

\section{RESUMO}

O presente artigo aborda as atividades de ensino-aprendizagem da História Indígena Guarani realizadas com os Professores(as) em Formação em Ciências Humanas na UNIPAMPA, Campus São Borja, a partir da Arqueologia Experimental. O objetivo central das atividades realizadas foi colaborar com a formação inicial dos professores(as) que irão atuar na educação básica, bem como difundir a importância da Arqueologia nos espaços escolares. Nessa perspectiva, aliaram-se à teoria das componentes curriculares: Metodologia para o Ensino em Ciências Humanas; Educação e Identidade na Fronteira Oeste; Educação e Patrimônio com as práticas de ensino e confecção de réplicas da cerâmica Guarani. As oficinas interdisciplinares possibilitaram aos licenciandos(as) um maior contato com a história indígena, sua arte e cultura, bem como permitiram a criação de espaços pedagógicos para a produção de recursos didáticos.

PALAVRAS-CHAVE: Arqueologia Experimental, cerâmica guarani, formação de professores, Educação Patrimonial.

\section{RESUMEN}

El presente artículo aborda las actividades de enseñanza-aprendizaje de la Historia Indígena Guaraní realizadas con los Profesores (as) en Formación en Ciencias Humanas en la UNIPAMPA, Campus São Borja a partir de la Arqueologia Experimental. El objetivo central de las actividades realizadas fue colaborar con la formación inicial de los profesores (as), que actuarán en la educación básica, así como difundir la importancia de la Arqueologia en los espacios escolares. En esa perspectiva, se alió la teoría de los componentes curriculares: Metodología para la Enseñanza en Ciencias Humanas; Educación e Identidad en la Frontera Oeste; Educación y Patrimonio con las prácticas de enseñanza y confección de réplicas de la cerámica Guaraní. Los talleres interdisciplinarios permitieron a los licenciandos (as) un mayor contacto con la historia indígena, su arte y cultura, así como permitieron la creación de espacios pedagógicos para la producción de recursos didácticos.

PALABRAS CLAVE: Arqueologia Experimental; cerámica guaraní; formación de profesores, Educación Patrimonial.

\section{ABSTRACT}

This article approaches the teaching and learning activities of the Guarani Indigenous History carried out with the Teachers in Human Sciences Training at UNIPAMPA, São Borja, Campus from Experimental Archeology. The central objective of the activities was to collaborate with the initial training of teachers, who will act in basic education, as well as to disseminate the importance of Archeology in school spaces. In this perspective, the theory of the curricular components was allied: Methodology for the Teaching in Human Sciences;

\footnotetext{
${ }^{1}$ Doutora em Arqueologia pela Universidad Nacional del Centro de la Provincia de Buenos Aires, Olavarría. E-mail: vivianepoueyvidal@gmail.com.
}

\begin{tabular}{|l|l|l|l|l|l|l|}
\hline (C) Rev. Arqueologia Pública & Campinas, SP & v.12 & n.1 & p. & Jul/2018 & ISSN 2237-8294
\end{tabular}


Education and Identity in the West Frontier; Education and Heritage with the practices of teaching and making replicas of Guaraní ceramics. The interdisciplinary workshops allowed graduates greater contact with indigenous history, their art and culture, as well as, they allowed the creation of pedagogical spaces for the production of didactic resources.

KEYWORDS: Experimental Archeology, ceramic guaraní, teacher training, Heritage Education.

\section{INTRODUÇÃO}

O curso de licenciatura em Ciências Humanas do Campus São Borja da UNIPAMPA possui como missão a formação de professores interdisciplinares, que são habilitados para atuar na Educação Básica: Ciclo II do Ensino Fundamental (séries de $6^{\circ}$ a $9^{\circ}$ ano), nas áreas de História e Geografia, e no Ensino Médio, nas áreas de História, Geografia, Sociologia e Filosofia. O curso visa ainda a "realizar a articulação entre teoria e as realidades sociais de forma crítica, na prática da docência e da pesquisa" (PPC-UNIPAMPA, 2014, p. 46).

Nessa perspectiva, as aulas no curso de Ciências Humanas são planejadas de modo interdisciplinar, visando ao diálogo entre as quatro áreas das Ciências Humanas: História, Geografia, Sociologia e Filosofia. As atividades de ensino realizadas a partir da História Indígena Guarani dialogaram também com as seguintes ciências: a Arqueologia, a Antropologia, a Etnohistória e a EtnoArqueologia. Este diálogo interdisciplinar entre as Ciências Humanas e as Ciências Sociais busca formar professores(as)-pesquisadores(as) habilitados(as) para aliarem o conhecimento teórico à prática de ensino nas escolas.

Como supracitado, a temática deste artigo aborda o "saber fazer cerâmica", um conhecimento milenar que por décadas foi atividade impensável na Educação Básica no município de São Borja-RS, habitado durante o período pré-colonial e missioneiro pela etnia indígena GuaraniCeramista, com evidências corroboradas através das pesquisas arqueológicas. Provavelmente, essa lacuna no conhecimento dos professores(as) sobre as etnias indígenas, sua cultura material, imaterial e artística deve-se à ausência dessas temáticas em suas formações iniciais e continuadas.

Nesse sentido, ao destacar o ensino interdisciplinar na formação inicial dos professores(as) em Ciências Humanas, buscou-se inserir a Ciência Arqueológica como metodologia de pesquisa e ensino-aprendizagem, que possibilita a construção do conhecimento teórico-prático sobre a etnia indígena Guarani. É pertinente destacar que a Arqueologia brasileira ainda é pouco conhecida na Educação Básica, uma vez que a maioria dos professores em atuação não teve contato com a ciência na universidade. Um amplo número de cursos de formação de professores(as) em História não possui as componentes curriculares de Arqueologia e História Indígena Pré-colonial em seu Projeto Político Pedagógico (PPC).

O diferencial do curso de licenciatura em Ciências Humanas, entretanto, está em possuir várias componentes curriculares de Prática Docente e Educação Patrimonial (doravante EP), propiciando, como supracitado, um diálogo interdisciplinar entre as quatro áreas de conhecimento do curso com a Arqueologia e as Ciências Sociais correspondentes. Ademais, permite aos professores(as) em formação uma experiência prática ainda na universidade, ou seja, eles aprendem a confeccionar os seus recursos pedagógicos para o ensino de forma didática e lúdica nas escolas. 
Nessa medida, justifica-se a proposta em formar professores interdisciplinares em Ciências Humanas a partir do conhecimento da Arqueologia Experimental e da Arte da Cerâmica. Desse modo, o planejamento das aulas na universidade demandou um diálogo com a EP transformadora de Maria de Lourdes Horta (2006). A autora aponta que a EP é uma metodologia de valorização do patrimônio cultural que deve ser inserida no currículo escolar como um tema transversal. Contudo, muitos educadores ainda se questionam: como será possível utilizar a Arqueologia em sala de aula ao abordar conteúdos diferenciados?

Nesse contexto, o presente artigo visa a demonstrar a importância da formação inicial e continuada dos professores(as) a partir de metodologias interdisciplinares de ensino e pesquisa, que aliem a teoria com a prática de ensino. Em relação à formação de professores interdisciplinares, Salomão et al. (2017) enfatizam que a vivência do trabalho interdisciplinar aliada à formação teóricoprática integra as Diretrizes Curriculares Nacionais para a Formação Inicial e Continuada dos Profissionais da Educação Básica, "por meio do Parecer CNE/CP n 2, de 9 de junho de 2015 (BRASIL, 2015) e da Resolução CP/CNE n² 2, de 01 de julho de 2015" (BRASIL, 2015b, p. 7-8 apud SALOMÃO et al., 2017, p. 25).

\section{ARQUEOLOGIA E O PATRIMÔNIO CULTURAL}

A Arqueologia é uma ciência social que dialoga constantemente com outras ciências, como a Geologia, Paleontologia, Paleoecologia, Biologia, História, Geografia, Sociologia, entre outras. Apresentar a Arqueologia como disciplina integral em um breve texto é complexo, visto que é preciso resumir em poucas páginas uma ciência multidisciplinar. Destaca-se que o público não especialista tem, na maioria das vezes, uma visão distorcida da disciplina. A maioria dos leigos considera "a Arqueologia como uma prática científica que se reduz à escavação das pirâmides do Egito, ou dos monumentos da Grécia Clássica, ou discorre num mundo de aventuras e explorações ao estilo "Indiana Jones" (POLITIS, 2004, p. 5). Entretanto, poucos acreditam que as pinturas rupestres, os índios que habitaram as costas do Brasil há milhares de anos, as vasilhas de cerâmica e os artefatos talhados na pedra amplamente encontrados na América do Sul são projetos sérios de Arqueologia. Em geral, pensa-se que são temas menores, pouco dignos do trabalho a ser desenvolvido e insignificantes, se comparamos ao "Partenon, a Esfinge de Gizé ou com algum templo de Camboja" (POLITIS, 2004; FUNARI, 2010).

Contudo, tais percepções errôneas devem-se à forma do ensino, ou seja, o que é compreendido e difundido como patrimônio cultural e o que se reconhece como parte de uma cultura. No mundo ocidental, falar em patrimônio histórico era referir-se ao monumento a construções arquitetônicas. Atualmente, o patrimônio vem sendo reconhecido por um termo mais abrangente, o denominado "patrimônio cultural", entendido como o conjunto dos bens culturais, alusivos às identidades coletivas e ao sentimento de pertencimento a determinada cultura. Essa nova perspectiva de abordar o tema fortaleceu a noção de patrimônio, englobando as múltiplas paisagens, arquiteturas, tradições, peculiaridades gastronômicas, expressões de arte, documentos e sítios arqueológicos, os quais passaram, a partir daí, a serem valorizados pelas comunidades e organismos governamentais nas esferas local, estadual, nacional e até mesmo internacional (THOMAZ, 2010).

No Brasil, a preocupação com os bens culturais possui raízes no final do século XVIII, quando ocorreu a Revolução Francesa. Nesse período, o Estado francês propôs-se a conservar os bens potencialmente capazes de fortalecer a sua identidade enquanto instância suprema. Nesse contexto, a noção de patrimônio é, portanto, representada como ideia de nação, e foi precedida, na civilização ocidental, pela autonomização das noções de arte e de história. O histórico e o artístico

\begin{tabular}{|l|l|l|l|l|l|l|}
\hline C C Rev. Arqueologia Pública & Campinas, SP & v.12 & n.1 & p. & Jul/2018 & ISSN 2237-8294
\end{tabular}


assumem, nesse caso, uma dimensão instrumental, sendo utilizados na construção de uma representação de nação (FONSECA, 1997).

O conceito de "Patrimônio Histórico e Artístico Nacional brasileiro" possui o mesmo sentido supracitado, isto é, atribuir identidade ao país. A preocupação com a preservação do patrimônio histórico nacional, especialmente dos bens imóveis fora do âmbito dos museus, adquire um significado mais relevante a partir da década de 1920, considerando que a falta de preocupação com esses bens estava comprometendo sua conservação, despertando a atenção de intelectuais, que denunciavam o descaso com as cidades históricas e a depredação do que seria um "tesouro" nacional. Nesse caso, os intelectuais observaram que a imobilidade das elites nacionais e do Estado diante dessa questão poderia acabar comprometendo o próprio país diante das nações tidas como civilizadas, assunto este que se tornou o centro das preocupações do Governo, no Congresso Nacional, nas instituições culturais e na imprensa (RODRIGUES, 1998).

A partir da Constituição de $1934^{2}$, artigo 10, observa-se, pela primeira vez no Brasil, a noção jurídica de Patrimônio Histórico e Artístico Nacional. Este artigo visava a responsabilizar o poder público pela preservação dos monumentos de valor histórico ou artístico de importância nacional: Art 10 - Compete concorrentemente à União e aos Estados: III - proteger as belezas naturais e os monumentos de valor histórico ou artístico, podendo impedir a evasão de obras de arte. Com o Decreto - Lei $n^{\circ} 25$, de 30 de novembro de $1937^{3}$, firmado por Getúlio Vargas, então Presidente da República, cria-se o SPHAN - Serviço do Patrimônio Histórico e Artístico Nacional.

O SPHAN foi estruturado por intelectuais e artistas brasileiros do período. Nesse contexto, definiu-se Patrimônio Histórico e Artístico Nacional como "o conjunto dos bens móveis e imóveis existentes no país e cuja conservação seja de interesse público, quer por sua vinculação a fatos memoráveis da história do Brasil, quer por seu excepcional valor arqueológico ou etnográfico, bibliográfico ou artístico" (Decreto $n^{\circ} 25,1937$ ). Após a assinatura do Decreto de Lei $n^{\circ} 25$, foi possível dispor de uma regulamentação apropriada de proteção dos bens culturais no Brasil. As constituições brasileiras posteriores a esse decreto têm apenas ratificado a noção de patrimônio em termos de direitos e deveres envolvendo tanto o Estado quanto os cidadãos (FONSECA, 1997).

É possível observar que o conceito de "patrimônio nacional", até o final da década de 1970, manteve-se direcionado à preservação de bens imóveis. Nesse caso, foram também aderidos os conceitos de sítios e conjuntos arquitetônicos representativos para a memória, a construção e reconstrução do sentimento de pertencimento à cultura brasileira. Tais conceitos foram utilizados no processo de ensino e formação dos valores civis, buscando construir e fortalecer um sentimento de nacionalidade comum a todo brasileiro:

\begin{abstract}
Consagrados pelo poder público, estes bens ganhavam uma espécie de aura que os situava acima do presente, dos conflitos e diferenças manifestos no cotidiano. Estavam ali preservados, apropriados, a informar o passado como uma das instâncias do conhecimento social, como joias culturais, para serem vistos com a reverência própria que merecem os lugares fundadores; para serem estudados em sua forma e técnica construtiva; para ensinarem o que era brasileiro. (RODRIGUES, 1998, p. 90).
\end{abstract}

No entanto, o conceito dedicado somente à preservação de bens imóveis foi repensado, sendo adotadas medidas de preservação referentes a outras áreas da dinâmica cultural brasileira.

\footnotetext{
${ }^{2}$ Constituição de 1934. Disponível em: <http://www.planalto.gov.br>. Acesso em: out. 2017

${ }^{3}$ Decreto de Lei n. de 30 de novembro de 1937. Artigo 1․ Disponível em: <http://www.antt.gov.br>. Acesso em: out. 2017.
}

\begin{tabular}{|l|l|l|l|l|l|l|} 
(C) Rev. Arqueologia Pública & Campinas, SP & v.12 & n.1 & p. & Jul/2018 & ISSN 2237-8294
\end{tabular}


Dessa maneira, torna-se possível o tombamento não só de bens materiais, mas também de bens de natureza imaterial. De acordo com o artigo $n^{\circ} 216$ da Constituição Federal de 1988, que salienta:

\begin{abstract}
Constituem patrimônio cultural brasileiro os bens de natureza material e imaterial, tomados individualmente ou em conjunto, portadores de referência à identidade, à ação, à memória dos diferentes grupos formadores da sociedade brasileira, nos quais se incluem: as formas de expressão; os modos de criar, fazer e viver; as criações científicas, artísticas e tecnológicas; as obras, objetos, documentos, edificações e demais espaços destinados às manifestações artístico-culturais; os conjuntos urbanos e sítios de valor histórico, paisagístico, artístico, arqueológico, paleontológico, ecológico e científico. (FUNARI, 2006).
\end{abstract}

As disposições contidas no artigo $n^{\circ} 215$ enfatizam a proteção às manifestações populares indígenas e afro-brasileiras ou de quaisquer outros segmentos étnicos nacionais, propondo, inclusive, a fixação de efemérides ou datas comemorativas concernentes aos seus respectivos interesses. É incluída, ainda, a defesa do meio ambiente, da qualidade de vida nos centros urbanos e da pluralidade cultural demonstrando avanços na luta pela cidadania e por políticas preservacionistas nos anos que se seguiram. Com base nessa Constituição, é incluída nos projetos de preservação patrimonial a preocupação com os bens que transcendem o material, sendo valorizados outros aspectos da sociedade, como a defesa do meio ambiente e a pluralidade cultural do povo brasileiro, tanto de origem material quanto imaterial (FUNARI, 2006, p. 51).

\title{
EDUCAÇÃO PATRIMONIAL E A ARQUEOLOGIA EXPERIMENTAL
}

A Educação Patrimonial, para Horta et al. (1999, p. 6), especialistas e pioneiras na temática no Brasil, trata-se de "um processo permanente e sistemático de trabalho educacional centrado no Patrimônio Cultural como fonte primária de conhecimento e enriquecimento individual e coletivo". $O$ trabalho da EP busca levar as crianças e adultos a um processo ativo de conhecimento, apropriação e valorização de sua herança cultural, capacitando-os para um melhor usufruto desses bens e propiciando a geração e a produção de novos conhecimentos, num processo contínuo de criação cultural.

Horta (2006) considera que o conhecimento crítico e a apropriação consciente pelas comunidades do seu Patrimônio são fatores indispensáveis no processo de preservação sustentável desses bens, assim como no fortalecimento dos sentimentos de identidade e cidadania. Nesse sentido, a EP é um instrumento de "alfabetização cultural" que possibilita ao indivíduo realizar a leitura do mundo em seu entorno, levando-o à compreensão do universo sociocultural e da trajetória histórico-temporal em que está inserido (HORTA, 2006; VIDAL, 2010).

Por conseguinte, o processo de reconhecimento do seu patrimônio cultural leva ao reforço da autoestima dos indivíduos e comunidades e à valorização da cultura brasileira, compreendida como múltipla e plural. $O$ diálogo estabelecido durante o processo educacional estimula e facilita a comunicação e a interação entre os professores, seus alunos, as comunidades e os agentes responsáveis pela preservação e estudo dos bens culturais, possibilitando a partilha de conhecimentos e a formação de parcerias para a proteção e valorização desses bens (HORTA, 2006).

A EP caracteriza-se por todos os processos educativos, formais e não formais tendo como foco central o Patrimônio Cultural, a fim de colaborar para seu reconhecimento, sua valorização e preservação. O IPHAN (2014) considera que os processos educativos devem primar pela construção

\begin{tabular}{|l|l|l|l|l|l|l|}
\hline (C) Rev. Arqueologia Pública & Campinas, SP & v.12 & n.1 & p. & Jul/2018 & ISSN 2237-8294
\end{tabular}


coletiva e democrática do conhecimento, isto deve ocorrer por meio do diálogo permanente entre os agentes culturais e a participação efetiva das comunidades detentoras e produtoras das referências culturais (IPHAN, 2014, p. 19).

A metodologia específica da EP pode ser aplicada a qualquer evidência material ou manifestação da cultura, seja um objeto ou conjunto de bens, um monumento ou um sítio histórico ou arqueológico. Essa metodologia também pode ser aplicada ao estudo de uma paisagem natural, um parque ou uma área de proteção ambiental, um centro histórico urbano ou uma comunidade da área rural, uma manifestação popular de caráter folclórico ou ritual, um processo de produção industrial ou artesanal, tecnologias e saberes populares e qualquer outra expressão resultante da relação entre os indivíduos e seu meio ambiente (SOARES, 2003; HORTA, 2006; FUNARI, 2010).

A Arqueologia Experimental possibilita a compreensão dos modos de produção, interações e relações familiares, sociais, religiosas e econômicas dos povos pré-coloniais, que manifestaram-se por meio da fala, da arte e da cultura material. Nesse sentido, a Arqueologia Experimental pode ser compreendida como os estudos que "consistem na tentativa de reprodução experimental das técnicas utilizadas pelas culturas originais para a confecção de seus artefatos através da observação do processo de produção e do resultado final". Além de possibilitar uma análise completa dos artefatos arqueológicos originais em laboratório, reunindo um conhecimento empírico e teórico (SOARES et al., 2015).

Como mencionado por Di Baco e Faccio (2014), a Arqueologia Experimental exige estudos prévios a longo prazo, implicando no envolvimento de tecnologias e métodos específicos para trabalhar com o material arqueológico. Os autores enfatizam que, na maioria das vezes, os testes resultam em uma "nova tecnologia e ao estabelecimento de uma tradição tecnológica". Destacam ainda que "os conhecimentos adquiridos nos testes experimentais com a cerâmica Guarani advêm de uma 'tradição tecnológica' desenvolvida e praticada desde a metade da década de 1990, na Universidade Estadual Paulista (FCT-UNESP)" (DI BACO \& FACCIO, 2014, p. 56).

Nessa perspectiva, Funari e Pinsky (2002) consideram que a "cultura não se restringe ao estudo formal, ao contrário; todas as nossas ações fazem parte da cultura" (FUNARI; PINSKY, 2002, p. 9). Em relação aos vestígios da cultura material, torna-se papel do pesquisador buscar reconstituir essas ações da sensibilidade com compreensão do fato histórico no intento de legar à sociedade futura o entendimento de si própria (DUARTE, 2017).

Nesse sentido, a Arqueologia Experimental pode ser compreendida como o estudo que consiste na tentativa de reprodução experimental das técnicas e procedimentos utilizados pelas culturas nativas na produção de seus artefatos e utensílios domésticos e, "através da observação do processo de produção e do resultado final, permitir uma análise mais completa dos artefatos originais em laboratório, já que será agregado um conhecimento empírico ao teórico" (BELLETI et al. 2013, p. 1).

Portanto, conforme Cerezer (2008) compreende, a experimentação arqueológica surge como um complemento aos estudos tradicionais relacionados à cerâmica, como a arqueometria, seriação e tipologia. No entanto, a Arqueologia Experimental não substitui os métodos de análise, exclusivamente possibilita criar hipóteses a serem confirmadas, repensando problemáticas de estudo.

\section{OCUPAÇÕES PRÉ-COLONIAIS GUARANI NO RIO GRANDE DO SUL}

\begin{tabular}{|l|l|l|l|l|l|l|}
\hline (C) Rev. Arqueologia Pública & Campinas, SP & v.12 & n.1 & p. & Jul/2018 & ISSN 2237-8294
\end{tabular}


De acordo com Schmitz (2006), escrever sobre a Arqueologia dos Guarani é mais fácil que a dos outros grupos pré-históricos do Rio Grande do Sul, porque conhecemos a sua economia, seus costumes, sua história colonial e o território que ocupavam. Para o autor, distintamente dos outros grupos indígenas e suas conexões históricas aos seus predecessores, como "os Guaianá (Kaingang) com a tradição Taquara, os Minuano com a tradição Vieira, esta dúvida não cabe absolutamente quando ligamos os Guaranis históricos com a tradição cerâmica chamada Tupiguarani" (SCHMITZ, 2006, p. 31).

No estudos arqueológicos realizados no Rio Grande do Sul, foi identificada uma conexão inegável entre os Guarani históricos e os reconstruídos por meio da Arqueologia pré-colonial. Esta conexão é identificada a partir do primeiro período missionário espanhol (1626-1636), três das missões estudadas foram: Jesus Maria no município de Candelária, São Miguel no município de São Pedro do Sul e Candelária do Caazapámini no Município de São Luiz Gonzaga. No grupo guarani, não é fácil nem interessante separar os dados históricos dos arqueológicos, devido à sua íntima conexão, mas será preciso manejá-los simultaneamente, buscando uma antropologia e uma história dos agricultores do mato em todas as etapas da sua evolução. De certa forma, todas são hoje arqueológicas. A reconstituição da cultura Guarani deverá ser uma segunda etapa, na qual dados sobre o abastecimento, estrutura da casa e da aldeia, territorialidade, rituais de sepultamento, tecnologia e muitos outros terão de ser rigorosamente observados e elaborados (KERN, 1992; SCHMITZ, 2006).

Durante a colonização europeia no Rio Grande do Sul, de acordo com os relatos do missionário Montoya $(1876,1892)$, nos quais se encontram as maiores fontes de informações sobre os Guarani históricos, cerca de 200.000 pessoas falavam a língua guarani. As ocupações guarani estavam distribuídas por todas as áreas de mata subtropical, que se estende ao longo do rio Uruguai e seus afluentes, ao longo do rio Jacuí e seus tributários, ao longo da costa marítima e suas lagoas. $\mathrm{Na}$ região norte, estabeleciam fronteira com os grupos genericamente denominados Guaianá, ocupantes das matas com pinheiros, acima dos $300 \mathrm{~m}$ de altitude, e ao sul tinham como vizinhos Charrua e Minuano, ocupantes das áreas abertas no campo (MONTOYA, 1985; SCHMITZ, 2006).

Com base na sua economia e cultura, os Guarani foram usualmente denominados pelos antropólogos como "horticultores de floresta tropical", como existe ainda hoje na Amazônia. Sua economia baseava-se em pequenas roças ou hortas, abertas nas matas através de "queimadas". Não tinham animais domésticos, o que os obrigava a conseguir as proteínas por meio da caça, pesca e coleta. Os indígenas viviam concentrados em aldeias de casas coletivas, construídas com troncos e palha, numa clareira da mata. Eram consideradas aldeias pequenas as que tivessem de 200 a 300 habitantes, mas não sabemos qual seria o critério para considerar uma aldeia "grande"; certamente não mais que mil habitantes (KERN, 1992; SOARES, 1997).

A população possuía os seus líderes locais, convencionalmente chamados "caciques". A maior parte dirigia um pequeno grupo de famílias, geralmente aparentadas, que se concentravam dentro de uma casa, mas alguns exerciam influências mais amplas e conseguiam adesão de líderes espalhados sobre um grande território. Os caciques eram representantes de uma "nobreza" tradicional, com tendência a manter a posição na mesma família, e casavam-se com mulheres pertencentes à mesma nobreza. Não precisariam trabalhar, porque os seguidores os sustentavam. Tinham grande número de mulheres e filhos, além de criadas (KERN, 1992; SOARES, 1997). 
As maiores descobertas em sítios arqueológicos Guarani estão associadas às cerâmicas. A cerâmica era confeccionada pelas mulheres, que utilizavam o barro naturalmente adequado ou acrescentavam areia, grânulos diversos ou cacos velhos bem triturados ao barro excessivamente plástico. Os recipientes cerâmicos com distintas formas e tamanhos eram necessários para as atividades domésticas, como: a fermentação e conservação de bebidas para as festas coletivas exigiam grandes talhas de pescoço estreitado, que podiam atingir um metro de bojo e altura; para cozinhar eram mais úteis panelas de boca expandida, que podiam alcançar até $30 \mathrm{~cm}$ de bojo e para servir alimentos e bebidas havia necessidade de um grande número de pequenas tigelas (BROCHADO, 1989; SOARES, 1997; SCHMITZ, 2006).

As cerâmicas eram decoradas com padrões característicos dos Guarani: as vasilhas utilitárias do cotidiano apresentavam a superfície externa coberta com impressões regulares da polpa do dedo, borda da unha, ponta de um estilete, ou eram lisas; um outro conjunto, melhor trabalhado, era pintado, às vezes com um vermelho uniforme. Algumas cerâmicas apresentam desenhos geométricos variados em vermelho ou preto sobre uma base branca (BROCHADO, 1989).

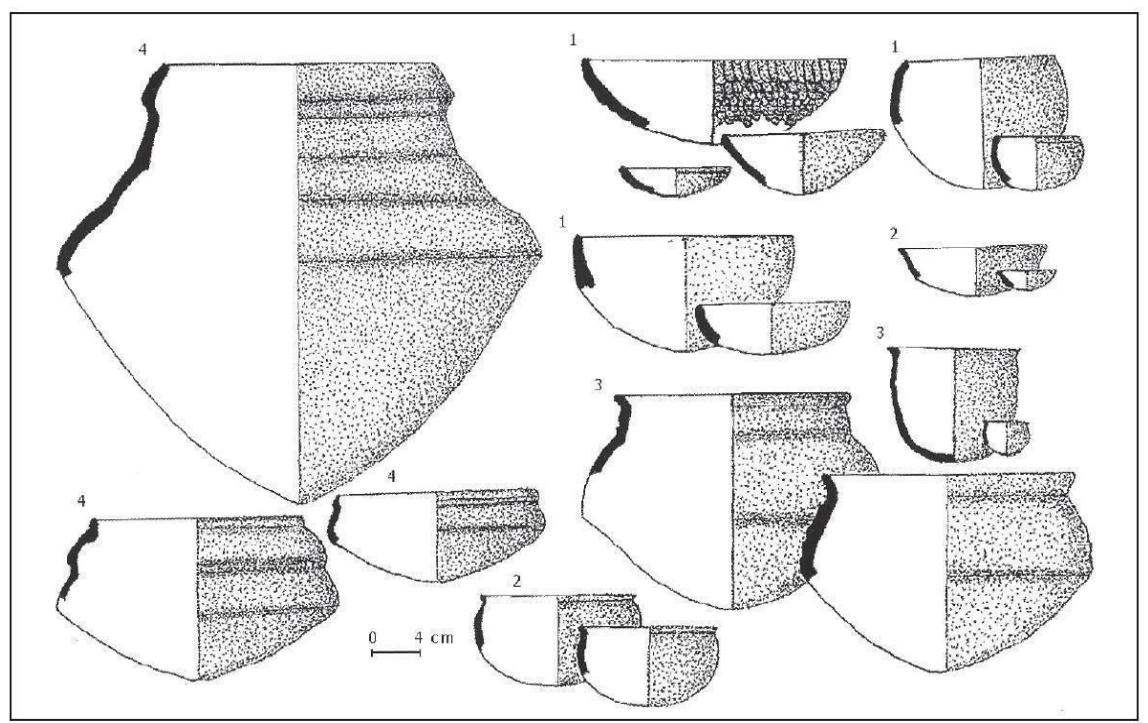

Figura 1. Formas de Cerâmicas Guarani reconstituídas no Pantanal. Fonte: Peixoto, 1998, p. 79.

\section{A FORMAÇÃO DE PROFESSORES(AS) E A IMPORTÂNCIA DO EDUCAR PELA PESQUISA}

A Formação de Professores(as) em Ciências Humanas a partir das oficinas e metodologias de ensino da Arqueologia Experimental e da História Indígena Guarani foi planejada na perspectiva de Pedro Demo (1996). Nesta, o autor afirma que a educação, no contexto do "educar pela pesquisa", deve ser entendida como "processo de formação da competência humana com qualidade formal e política, encontrando-se, no conhecimento inovador, a alavanca principal da intervenção da ética" (DEMO, 1996, p. 1).

Nessa medida, o estudo da História Indígena no curso de Ciências Humanas, que visa à formação de professores(as), é primordial, reconhecendo que o município de São Borja possui inúmeros sítios arqueológicos Pré-coloniais e Históricos/missioneiros, que foram habitados pelas distintas etnias indígenas Guarani, Kainguang; Charrua e Minuano, bem como pelas primeiras ocupações humanas caçadoras-coletoras paleoíndigenas, que chegaram ao atual Estado do Rio

\begin{tabular}{|l|l|l|l|l|l|l|l}
\hline C Rev. Arqueologia Pública & Campinas, SP & v.12 & n.1 & p. & Jul/2018 & ISSN 2237-8294
\end{tabular}




\section{Revista de Arqueologia Pública}

ARTIGO

Grande do Sul, especificamente na Fronteira Oeste, município de Uruguaiana entre 11.000-10.470 A.P (VIDAL, 2018).

Dessarte, o potencial de pesquisas arqueológicas e etnohistóricas do município, como supracitado, permitiu a construção de aulas interdisciplinares, que aliaram o conhecimento teórico à prática de ensino e aprendizagem. Para isso, previamente às "Oficinas Experimentais de Confecção de Réplicas das Cerâmicas Indígenas", os licenciados(as) realizaram a pesquisa teórica nos conteúdos de História, Etnohistória, Arqueologia, Antropologia e Geografia. Elaboraram resenhas teóricas e participaram de debates em sala de aula, aliando o conhecimento obtido às pesquisas de campo representadas pelas seguintes atividades: expedição arqueológica no Sítio Arqueológico de São Miguel das Missões; visitas guiadas à Fonte Arqueológica de São Pedro e aos Museus locais; assistiram a vídeos de escavações arqueológicas, Arqueologia Experimental e receberam orientações da docente sobre as técnicas de produção e decoração da superfície externa da cerâmica.

Por conseguinte, considera-se que a educação baseada na proposta pedagógica de educar pela pesquisa exige que o professor e o aluno compreendam a pesquisa como princípio científico e educativo e a tenham como atitude cotidiana. De acordo com Demo (1996), essa proposta deve basear-se no questionamento reconstrutivo "que engloba teoria e prática, qualidade formal e política, inovação e ética". Destacando a necessidade de uma prática que possibilite aos sujeitos da "ação educativa - ensinantes e aprendentes - a compreensão crítica e a participação ativa na e da realidade social na qual estão inseridos" (DEMO, 1996, p. 1; VIEIRA et al., 2016, p. 3).

Na perspectiva do ensino e formação de professores(as), a proposta pedagógica de Educar pela Pesquisa foi implementada nas atividades de ensino e aprendizagem da História Indígena Guarani. A metodologia de pesquisa e a realização de oficinas de cerâmicas baseadas na Arqueologia Experimental permitiram uma maior aproximação dos licenciandos(as) em Ciências Humanas ao contexto cultural indígena, suas tecnologias e significados - materiais, simbólicos, artísticos, religiosos, entre outros. Além de despertar nos futuros professores(as) os sentimentos de pertencimento, identidade e valorização do patrimônio cultural indígena de São Borja e municípios vizinhos.

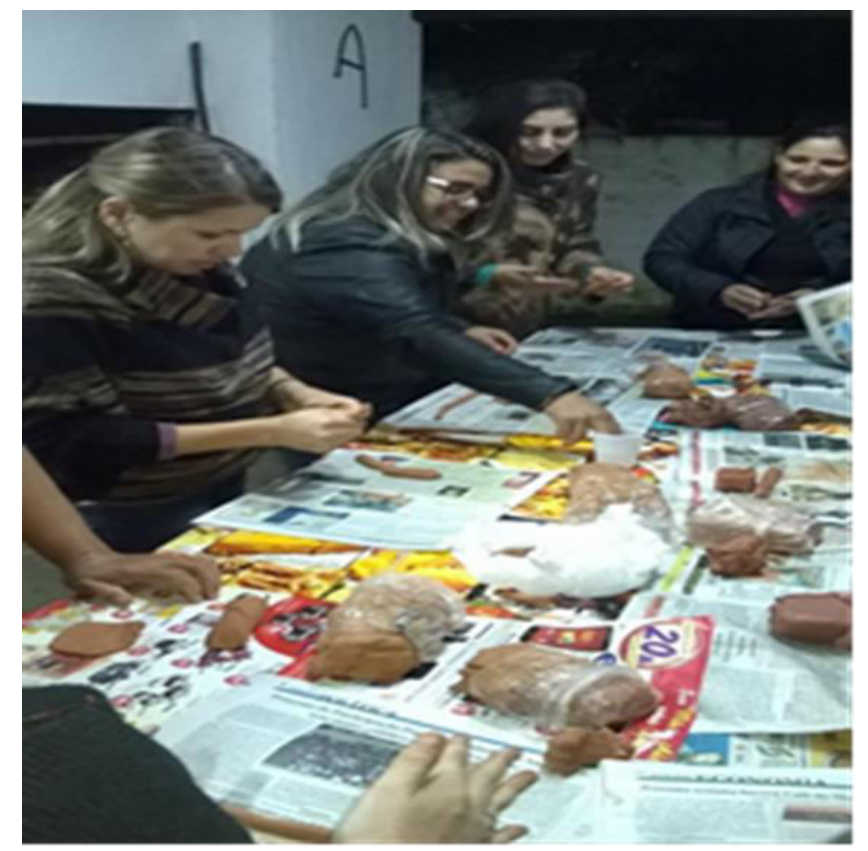


Figura 2. Oficina de Cerâmica com os professores(as) em formação em Ciências Humanas (UNIPAMPA, Campus São Borja). Fonte: arquivo pessoal da autora.
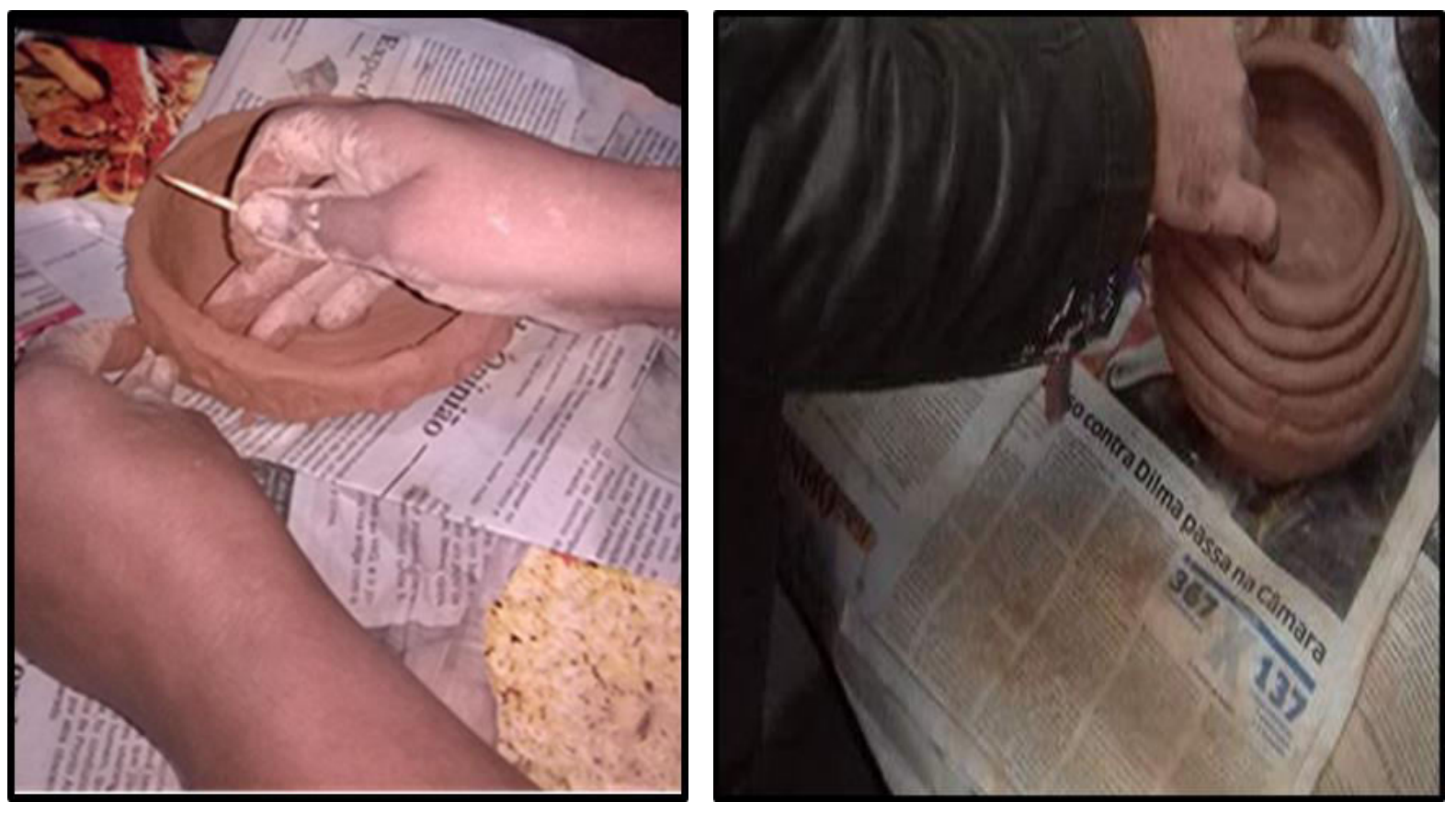


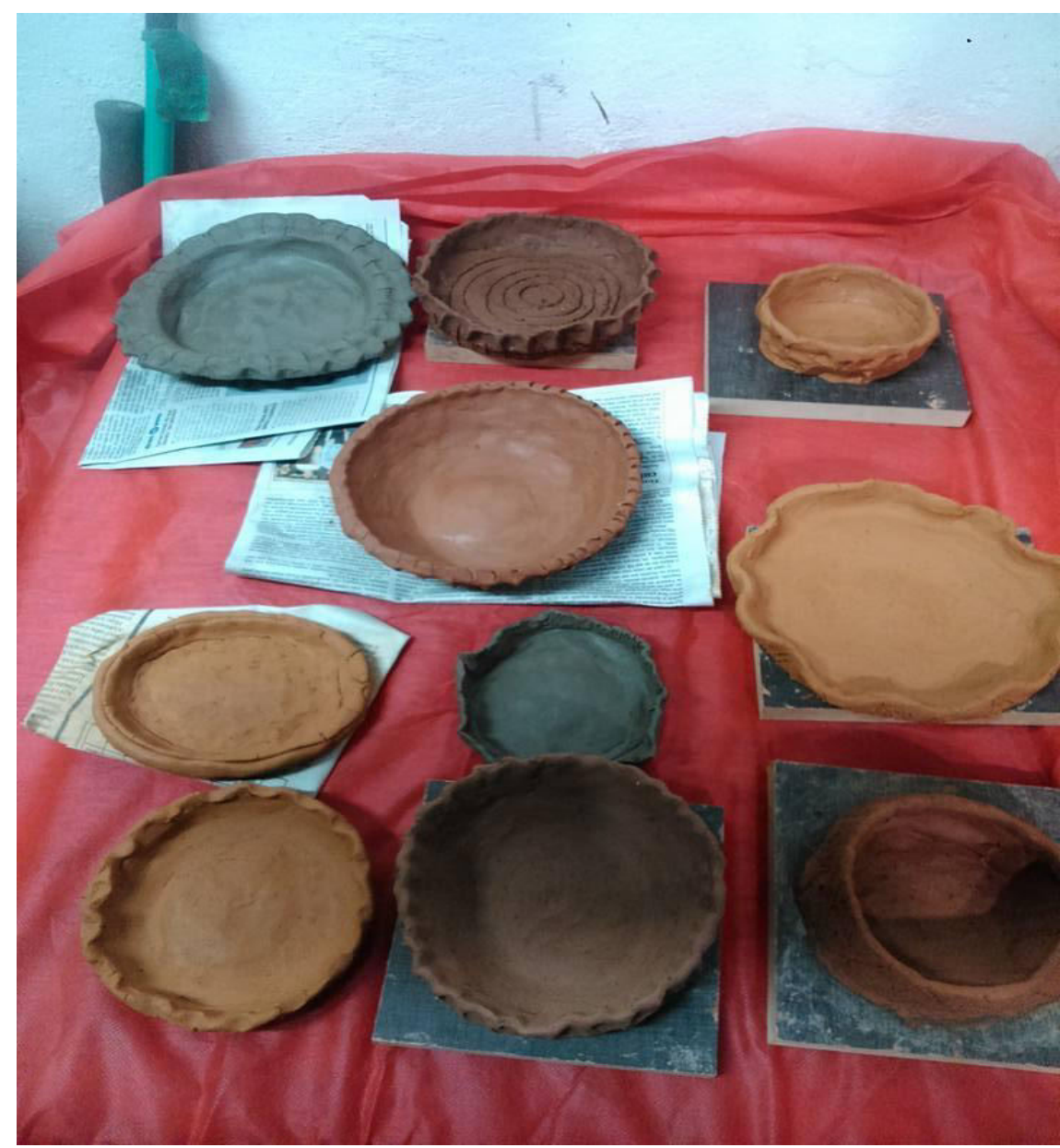

Figuras 3 (a-c). Réplicas de Cerâmicas Guarani ressignificadas e elaboradas pelos licenciados(as) em Ciências Humanas. Fonte: arquivo pessoal da autora.

Como mencionado, ao participarem da pesquisa sobre a história indígena pré-colonial do atual estado do Rio Grande do Sul, com ênfase para o estudo da etnia Guarani, os professores(as) em formação inicial em Ciências Humanas também aprenderam a confeccionar cerâmicas na universidade para o ensino nas escolas durante os estágios docentes supervisionados. Além dos estágios, as oficinas de EP e Ensino da História Indígena no município de São Borja também foram realizadas no PIBIC - Programa de Iniciação à Docência, no Colégio Estadual Getúlio Vargas em 2015. Sendo viável destacar que, atualmente, essas oficinas continuam sendo realizadas pelos professores(as) em formação inicial integrantes do PIBID em outras escolas.

Como um dos exemplos das Oficinas de Cerâmicas Guarani utilizadas como proposta de Trabalho de Conclusão de Curso em Ciências Humanas na cidade de São Borja, destaca-se a pesquisa de Vladmir Fortes (2017) na Escola Estadual Aparício Silva Rillo e na Escola Estadual Técnica Olavo Bilac. O objetivo da pesquisa e das oficinas nas escolas foi despertar o interesse dos alunos pela História do povo Guarani e sua contribuição cultural na constituição do atual município de São Borja, além de incentivar o fortalecimento de uma "identidade Guarani" para os estudantes locais.

O professor enfatiza ainda que durante as oficinas de cerâmicas Guarani nas escolas observou que os alunos "não conheciam a história indígena do município". Contudo, muitos alunos possuem as características físicas dos Guarani, mas não se reconheciam como descendentes

\begin{tabular}{|l|l|l|l|l|l|l|}
\hline (C) Rev. Arqueologia Pública & Campinas, SP & v.12 & n.1 & p. & Jul/2018 & ISSN 2237-8294 \\
\hline
\end{tabular}




\section{Revista de Arqueologia Pública}

ARTIGO

indígenas até o momento das oficinas. O autor menciona que foi possível perceber que os estudantes realmente se envolveram com as atividades, demonstrando maior interesse pela história indígena, "pois, durante as oficinas tinham muito cuidado ao manusear o material e preocupavam-se para que o resultado fosse o melhor possível" (FORTES, 2017, p. 43).

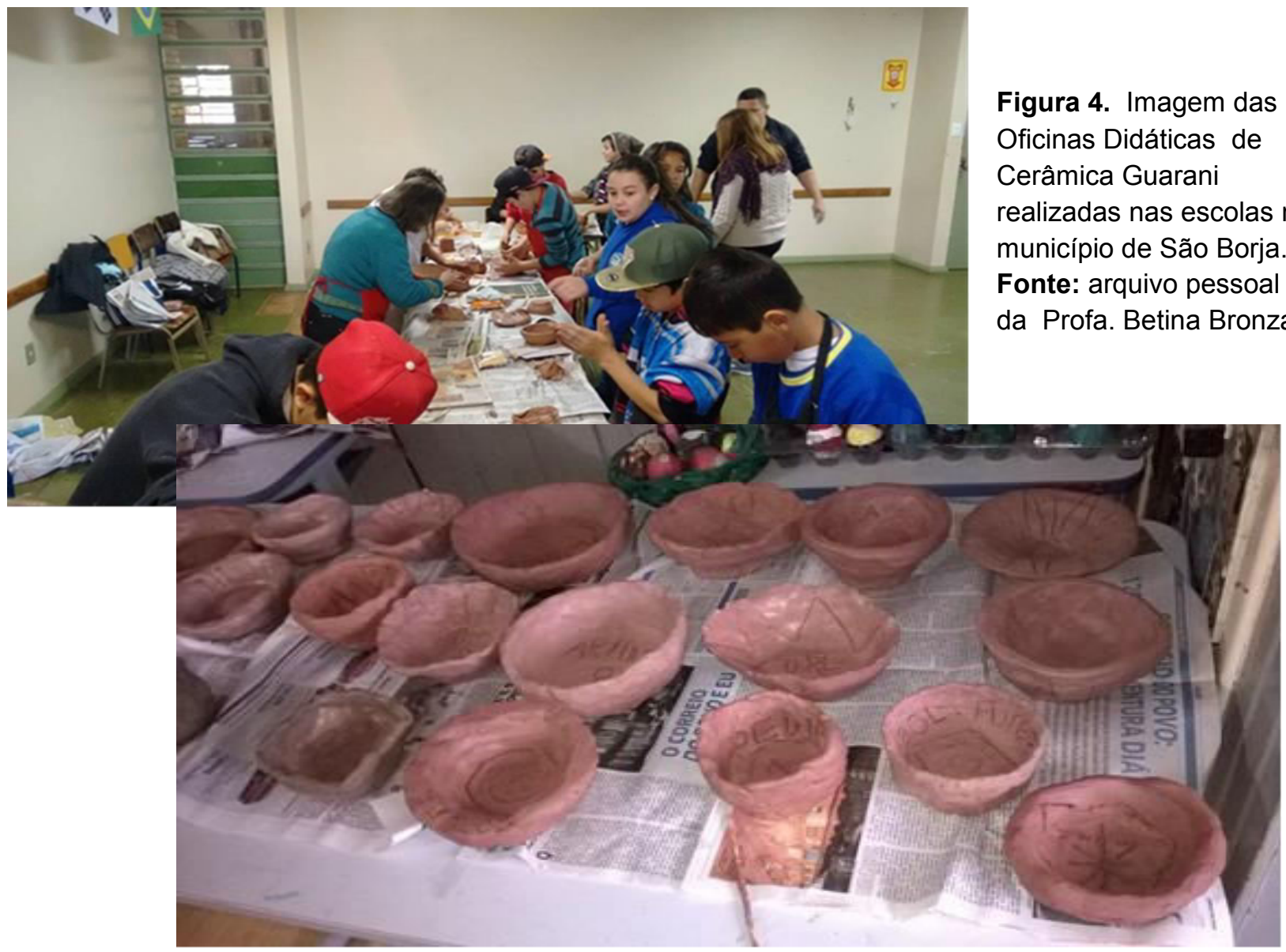

Figura 5. Réplicas das Cerâmicas Guarani elaboradas pelos estudantes dos $5^{\circ}$ e $6^{\circ}$ anos da Escola Estadual Aparício Silva Rillo. Fonte: arquivo pessoal da Profa. Betina Bronzani. 


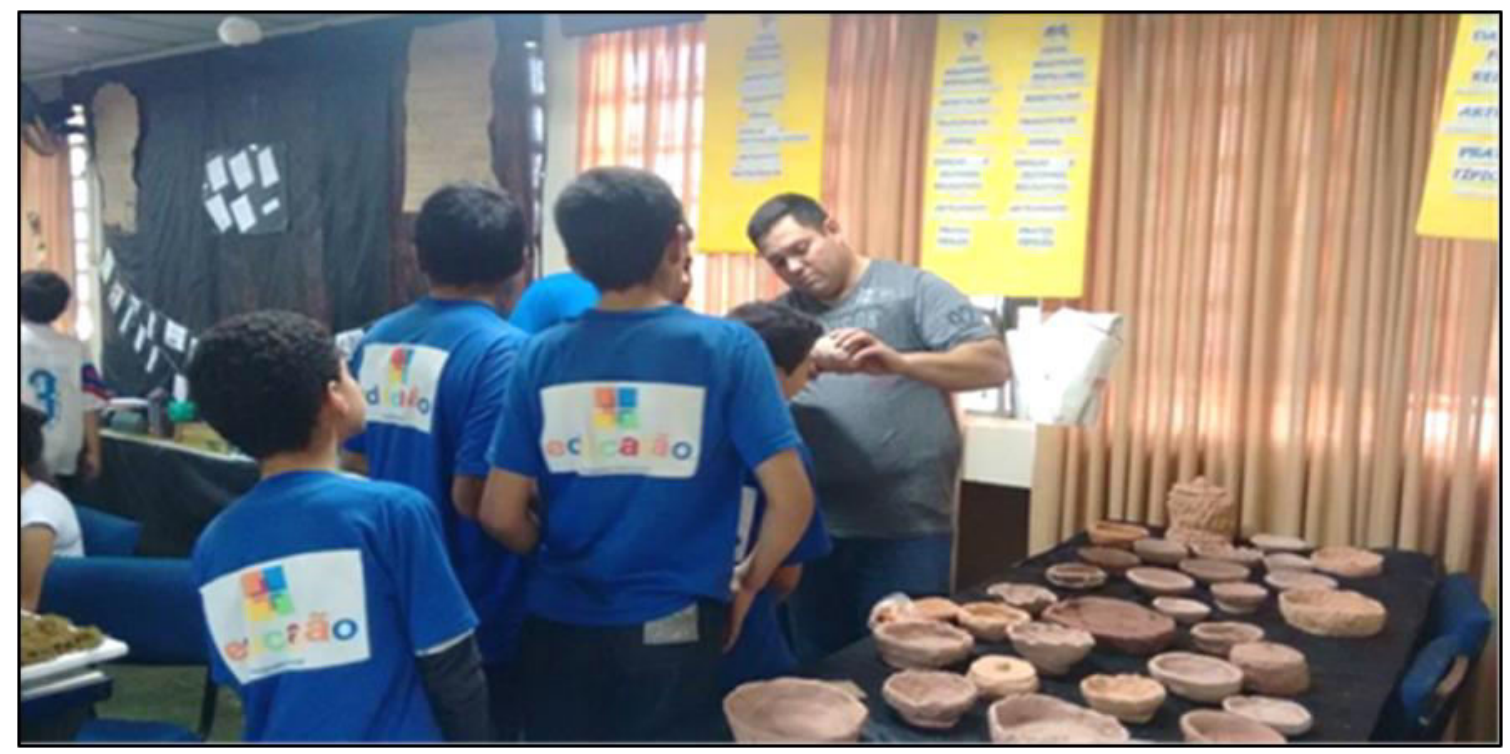

Figura 6. Exposição das Cerâmicas Confeccionadas pelos Estudantes durante a feira de Ciências da Escola Aparício Silva Rillo. Fonte: arquivo pessoal do Prof. Vladimir Fortes.

\section{CONSIDERAÇÕES FINAIS}

As atividades de pesquisas, ensino e aprendizagem a partir das Oficinas de Cerâmicas Indígenas Guarani com os professores(as) em formação em Ciências Humanas tornaram-se um diferencial nas aulas de História, Prática Docente e Educação Patrimonial na UNIPAMPA, Campus São Borja. Sendo possível exemplificar aos futuros professores(as) a importância do ensino interdisciplinar estar fundamentado na formação teórico-prática.

A pesquisa sobre a cultura dos antecedentes indígenas no município também despertou nos licenciandos(as) o interesse em conhecer as suas origens, além dos sentimentos de pertencimento e identidade étnica. Lembrando que um amplo número dos acadêmicos(as) em Ciências Humanas possui características físicas associadas às etnias indígenas que habitaram o município durante a História Pré-colonial e missioneira, são elas: Guarani, Kaingang, Charrua e Minuano.

Como supracitado, a metodologia de ensino e aprendizado a partir das oficinas de Cerâmica Guarani vem sendo amplamente utilizada nos estágios docentes supervisionados dos professores(as) em formação inicial em Ciências Humanas e nas atividades do PIBID. O trabalho de modelagem na argila nas oficinas de arte ceramista estimula a participação e um aprendizado lúdico para todos os alunos(as). Destaca-se ainda a contribuição do trabalho com a argila na inclusão de alunos com necessidades especiais na educação básica. Sendo evidenciados resultados positivos no processo cognitivo, interação com a turma, autoconfiança e autoestima dos alunos(as) incluídos.

A temática indígena também vem contribuindo na realização de pesquisas de conclusão do curso em Licenciatura em Ciências Humanas a partir de propostas de Educação Patrimonial nas escolas. É necessário destacar que todas as pesquisas realizadas até o momento são excelentes contribuições para a preservação e valorização do patrimônio cultural indígena, além de proporem metodologias diferenciadas para o ensino nas escolas. 


\section{REFERÊNCIAS BIBLIOGRÁFICAS}

BELLETI, Jaqueline da Silva et al. Arqueologia experimental: interpretação e produção de artefatos cerâmicos. In: XIV Congresso de Iniciação Científica. Pelotas, Universidade Federal de Pelotas, 2013. Disponível em:

<http://www.ufpel.edu.br/cic/2005/arquivos/indice_CH.htm>.

BROCHADO, José Proenza. Cerâmica Guarani. Porto Alegre: Ed. Posenato Arte e Cultura, 1989.

CEREZER, Jedson Francisco. Cerâmica Guarani. Manual de Experimentação Arqueológica. Habilis, Erexim, 2012.

DEMO, Pedro. Educar pela pesquisa. Campinas: Autores Associados, 1996.

DI BACO, H. M.; FACCIO, N. B. Tecnologia cerâmica Guarani e o estudo experimental da variabilidade cerâmica. Revista do Museu Arq. Etn., São Paulo, n. 24, p. 53-75, 2014.

DUTRA, E. Arqueologia Experimental e Ensino da Arte. Cadernos CEOM, Chapecó, v. 17. n. 18, p. 117-149, 2003.

FREITAS, Diana Paula Salomão de; MARTINS, Claudete Lima; MELLO, Elena Maria Billig. A Implementação da política de formação de professoras(es) no contexto do projeto Tertúlias Pedagógicas do Pampa Gaúcho. In: GRAP, Graciele; GRAP, Lucimara. (Org.).

Políticas públicas na educação brasileira: a formação inicial e continuada de docentes e gestores. Curitiba: Atena Editora, 2017.

FONSECA. Maria Cecília Londres. O patrimônio em processo: trajetória da política federal de preservação no Brasil. Rio de Janeiro: UFRJ/IPHAN, 1997.

FUNARI, Pedro Paulo. Arqueologia. São Paulo: Contexto, 2010.

Patrimônio histórico e cultural. Rio de Janeiro: Zahar, 2006.

FUNARI, Pedro Paulo; PINSKY, Jaime. (Orgs.). Turismo e Patrimônio Cultural. 2. ed. São

Paulo: Contexto, 2002.

HORTA, M. L. P. Fundamentos da Educação Patrimonial. In.: SALES, F. L. A Educação

Patrimonial e o Turismo: O caso da Aula no Museu do Museu Municipal de Caxias do

Sul/RS. Dissertação (Mestrado Acadêmico em Turismo). Universidade Caxias do Sul,

Caxias do Sul, 2006.

HORTA, Maria de Lourdes; GRUNBERG, Evelina; MONTEIRO, Adriane Queiroz. Guia Básico de Educação Patrimonial. Brasília: Instituto do Patrimônio Histórico e Artístico Nacional, Museu Imperial, 1999.

IPHAN. Educação Patrimonial: histórico, conceitos e processos. Brasília: Instituto do Patrimônio Histórico e Artístico Nacional, 2014. Disponível em:

<http://www.iphan.gov.br/baixaFcdAnexo.do?id=4240>. Acesso em: 10 nov. 2017.

KERN, Arno. A. Antecedentes Indígenas. Porto Alegre: Editora da Universidade Federal Rio Grande do Sul, 1992. 
MONTOYA, Pe. Antonio Ruiz de. Conquista Espiritual. Martins Livreiro. Porto Alegre, 1985.

POLITIS, GUSTAVO. Arqueologia e patrimônio não são apenas sobre o passado, Resenha. Revista Vitrivius, 2004.

RODRIGUES, Marly. Patrimônio, idéia que nem sempre é prática. DEPARTAMENTO DE PATRIMÔNIO HISTÓRICO E ARTÍSTICO DO DISTRITO FEDERAL. A Construção da cidade de Brasília. Brasília, 1998, p. 88.

SCHIMITZ, P. I. Migrantes da Amazônia: a Tradição Tupiguarani. In: Pré- História do Rio Grande do Sul. Arqueologia do Rio Grande do Sul, Brasil. Documentos 05. São Leopoldo, Instituto Anchietano de Pesquisas/Unisinos, 2006.

SILVA, Vladmir Fortes da. Educação Patrimonial Indígena nas Escolas: Um Resgate da Cultura Guarani na Cidade de São Borja/Rio Grande do Sul. TCC - Trabalho de Conclusão do Curso em Ciências Humanas, 2017.

SOARES, A.; CEREZER, J.; PERIUS, E.; AREND, J. Buscando a Socialização do Conhecimento Através da Arqueologia Experimental. Trabalho apresentado do II Congresso de Arqueologia de La Cuenca de La Plata, San José de Mayo, Uruguai, 2015.

SOARES, André. Educação patrimonial: relatos e experiências. Santa Maria: Editora UFSM, 2003.

SOARES, A. L. R. Guarani: Organização Social e Arqueologia. Porto Alegre: EDIPUCRS, 1997.

TOMAZ, Paulo Cesar. A Preservação do Patrimônio Cultural e sua Trajetória no Brasil. Fenix Revista de História e Estudos Culturais, 2010.

VIDAL, Pouey Viviane. La Ocupación Cazadora - Recolectora Durante la Transición Pleistoceno - Holoceno en el Oeste de Rio Grande do Sul-Brasil: GeoArqueologia de los Sítios en la Formación Sedimentária Touro Passo. Buenos Aires: UNICEN, 2018. (Tese de Doutorado em Arqueologia) - UNICEN, Buenos Aires, 2018.

Arqueologia de Resgate e Seu Papel Social: A Educação Patrimonial como "Alfabetização Cultural. 2010. Disponível em: $<$ http://www.historiaehistoria.com.br/materia.cfm?tb=Arqueologia\&id=38>. Acesso em: 5 nov. 2017.

VIEIRA, L. A.; FRANCA, D. M. R. V.; FARIAS, E. R. S.; JABUR, S. S.; CLARO, G. R. Educar e aprender pela pesquisa: uma opção metodológica à construção dos saberes. In: Conferência Internacional Saberes para uma Cidadania Planetária, 2016, Fortaleza.

Anais.... Fortaleza: a Universidade Católica de Brasília ? UCB e pela Universidade Estadual do Ceará ? UECE, 2016. 